\title{
Variation in species light acquisition traits under fluctuating light regimes: implications for non- equilibrium coexistence
}

Alexis Guislain (1) http://orcid.org/0000-0003-4176-4878, Beatrix E. Beisner (1) https://orcid.org/0000-0001-6972-6887, Jan Köhler

DOI

10.1111/oik.05297

Original publication date

16 November 2018

Document version

Accepted version

Published in

Oikos

Citation (Vancouver)

Guislain A, Beisner BE, Köhler J. Variation in species light acquisition traits under fluctuating light regimes: implications for nonequilibrium coexistence. Oikos. 2019;128(5):716-28. 
1 Variation in species light acquisition traits under fluctuating light regimes:

2 implications for non-equilibrium coexistence

3

4

\section{Abstract}

5 Resource distribution heterogeneity offers niche opportunities for species with different

6 functional traits to develop and potentially coexist. Available light (photosynthetically

7 active radiation or PAR) for suspended algae (phytoplankton) may fluctuate greatly over

8 time and space. Species-specific light acquisition traits capture important aspects of the

9 ecophysiology of phytoplankton and characterize species growth at either limiting or

10 saturating daily PAR supply. Efforts have been made to explain phytoplankton

11 coexistence using species-specific light acquisition traits under constant light conditions,

12 but not under fluctuating light regimes that should facilitate non-equilibrium

13 coexistence. In the well-mixed, hypertrophic Lake TaiHu (China), we incubated the

14 phytoplankton community in bottles placed either at fixed depths or moved vertically

15 through the water column to mimic vertical mixing. Incubations at constant depths

16 received only the diurnal changes in light, while the moving bottles received rapidly

17 fluctuating light. Species-specific light acquisition traits of dominant cyanobacteria

18 (Anabaena flos-aquae, Microcystis spp.) and diatom (Aulacoseira granulata, Cyclotella

19 pseudostelligera) species were characterized from their growth-light relationships that

20 could explain relative biomasses along the daily PAR gradient under both constant and 
21 fluctuating light. Our study demonstrates the importance of interspecific differences in

22 affinities to limiting and saturating light for the coexistence of phytoplankton species in

23 spatially heterogeneous light conditions. Furthermore, we observed strong intraspecific

24 differences in light acquisition traits between incubation under constant and fluctuating

25 light - leading to the reversal of light utilization strategies of species. This increased the

26 niche space for acclimated species, precluding competitive exclusion. These observations

27 could enhance our understanding of the mechanisms behind the Paradox of the Plankton.

29 Keywords: Fluctuating light; Light acquisition traits; Phytoplankton photoacclimation;

30 Niche partitioning; Non-equilibrium coexistence. 
It is well recognized that spatial and temporal heterogeneity offer niche opportunities for species with different ecological strategies to develop and potentially coexist (Chesson and Case 1986, Chesson 2000). Spatial heterogeneity reduces niche overlap, enabling coexistence by favouring different species in different local environments through environmental filtering. Temporal heterogeneity can also promote species coexistence through differential nonlinear species-specific responses to a fluctuating limiting factor; different species dominating at times when they are able to most actively use the resource (Chesson 2000, Adler et al. 2013). Thus, the impact of environmental variability on organisms may lead to different species performances and community composition than those measured under constant conditions (Koussoroplis et al. 2017). Empirical work on the effects of resource heterogeneity on species diversity maintenance and competition has been done on animals and terrestrial plants (see Amarasekare 2003 and Silvertown 2004 for reviews). In aquatic ecology, the coexistence of several phytoplankton species in a seemingly homogeneous environment was originally characterized as the "Paradox of the Plankton" (Hutchinson 1961).

As the major primary producers on Earth, phytoplankton are responsible for about half of the global net production of photosynthetic organisms (Field et al. 1998). Their community composition may greatly affect food webs and biogeochemical cycles (Falkowski et al. 1998, Litchman et al. 2015). Consequently, it is important to understand 
54 how environmental variation affects phytoplankton biodiversity. Phytoplankton have

55 very short generation times $(\approx 1$ day), are very easy to culture and have readily

56 measurable functional traits affecting fitness in a given environment. Thus, they provide

57 ideal models to test the effects of spatio-temporal environment variability on organisms.

58 Studies involving phytoplankton exposed to varying resource levels have focused

59 primarily on the effects of fluctuating nutrient supplies on species composition both in

60 the laboratory (Sommer 1984, 1985) and in nature (Beisner 2001). Light is another

61 essential resource for phytoplankton growth. Increasing efforts have been made to

62 better understand the effects of fluctuating intensities on phytoplankton physiology

63 under controlled (Nicklisch 1998, Havelková-Doušová et al. 2004, Shatwell et al. 2012)

64 and semi-natural conditions (Marra 1978, Köhler et al. 2018). Nevertheless, very few

65 studies have focused on the effects of fluctuating light levels on species competition and

66 coexistence (Litchman 1998, Flöder et al. 2002), solely investigating species diversity

67 and/or species-specific growth rates at either low or high light levels.

68 In nature, light availability for phytoplankton fluctuates on timescales ranging

69 from milliseconds to seasons (Falkowski 1984, Ferris and Christian 1991). Short-term

70 light fluctuations affect several physiological processes such as photosynthesis

71 (MacIntyre et al. 2000, Fietz and Nicklisch 2002), respiration (Avendaño-Coletta and

72 Schubert 2005) and consequently, growth (Shatwell et al. 2012, Köhler et al. 2018). 
Phytoplankton growth is non-linearly related to light availability, with a proportional increase in the limiting range of light intensities, constant growth at saturating light intensities, and a transition region around the onset of growth saturation. From such growth-light relationships, one may extract demographic traits of a population that can be seen to represent light acquisition traits as they provide reliable indicators of the ability of one species to grow at certain light intensities (Litchman et al. 2012). Traits include: the initial slope of the growth-light curve $(\alpha)$ which reflects the growth efficiency at limiting light; the maximum growth rate at saturating light $\left(\mu_{\max }\right)$; and the light intensity at zero growth $\left(P A R_{\text {comp }}\right)$, the so-called compensation light intensity (Fig. 1).

These light acquisition traits calculated from traditional growth-constant light relationships measured in the laboratory have been used to explain phytoplankton distributions along environmental light gradients (Schwaderer et al. 2011). Assuming no co-limitation with other factors such as grazing or nutrient supply, a species with the higher $\alpha$ is expected to outcompete the others under limiting light levels. Conversely, a species with the highest $\mu_{\max }$ is expected to outcompete the others under saturating light levels. However, it has been shown that the light acquisition traits are plastic and may have different values between incubations under constant and fluctuating light (Shatwell et al. 2012, Köhler et al. 2018). This trait plasticity reflects the timescale-dependent 
ecophysiological acclimation processes of phytoplankton to changing light intensities (Falkowski 1984, Ferris and Christian 1991). The acclimation mechanisms are speciesdependent (potentially even clonal-dependent, see Kardinaal et al. 2007) and should thus alter interspecific competition, promote coexistence or exclude inefficient species in diverse phytoplankton communities (Litchman 1998, Flöder et al. 2002). For instance, a species that is the best competitor at a certain constant light supply could coexist or even be displaced by a species with higher performance under fluctuating light of the same mean intensity.

In general, it is still unknown how species light acquisition trait variation under fluctuating light may alter niche partitioning and thus species coexistence in bulk phytoplankton communities. We made the first attempt to fill this gap by investigating the effects of fluctuating light on light acquisition traits and relative biomass of dominant phytoplankton species from a diverse community under semi-natural conditions. We deliberately measured the light acquisition traits in a community context, and not for species cultured separately, because species generally diverge more in resource use to reduce niche overlap in a multispecies context (Lawrence et al. 2012). We mimicked vertical mixing and induced fluctuating light regimes by computer-controlled motion of subsamples from a lake phytoplankton community in the frequently mixed, turbid, hypertrophic Lake TaiHu (China). The investigated community was adapted to Lake 
111 TaiHu's temperature and frequent mixing. It was incubated under nutrient-replete

112 conditions and drastically reduced grazing pressure. Thus phytoplankton dynamics were

113 expected to be mostly driven by rapid acclimation to light climate treatments within a

114 couple of days. We evaluated variation in light acquisition traits of phytoplankton

115 between stratified and mixed conditions and used these to describe realized light niches,

116 thereby improving understanding of non-equilibrium species coexistence under semi-

117 natural conditions. We hypothesized that in this natural phytoplankton community: (1)

118 fluctuating light would modify species-specific growth-light relationships and, as a

119 consequence, light acquisition traits $\left(\alpha, \mu_{\max }\right.$ and $\left.P A R_{\text {comp }}\right)$. A set of species light

120 acquisition traits was considered here as a light utilization strategy. Following support of

121 this first hypothesis, we then expected (2) a relative change in species biomass over the

122 light gradient (limiting vs. saturating light) and between subsamples incubated under

123 fluctuating light conditions relative to those experiencing constant light. We further

124 hypothesized that (3) niche partitioning of the dominant species was possible over 125 gradients of light and mixing depth in the water column. 
129 Lake TaiHu (China, $31^{\circ} 14^{\prime} \mathrm{N} 120^{\circ} 8^{\prime} \mathrm{E}$ ) is a very large $\left(2340 \mathrm{~km}^{2}\right)$, shallow (1.9 m mean 130 depth), hypertrophic, turbid and wind-exposed lake. Due to the intensification of human

131 activities in the catchment area, total nitrogen and phosphorus concentrations in the lake 132 have been increasing since the 1980's and resulted in intensified blooms occurring more 133 frequently (Duan et al. 2009, Qin et al. 2010). Cyanobacteria blooms can reach $1000 \mathrm{~km}^{2}$ 134 and may occur from May to November (Duan et al. 2009). The field experiment was 135 conducted from September $7^{\text {th }}$ to September $16^{\text {th }} 2016$, during the development of the 136 cyanobacteria bloom (mostly Microcystis spp.). Our experimental site was situated in the 137 Meiliang Bay of Lake TaiHu (northern part of the lake) on top of the Nanjing Institute of 138 Geography and Limnology (NIGLAS) landing, about 200 meters offshore. Prior to sampling, we removed any surface scums containing dying cyanobacteria

140 cells and sampled lake water at $30 \mathrm{~cm}$ depth to recover the natural phytoplankton 141 community. We filtered the water through a $100 \mu \mathrm{m}$ sized mesh to remove large 142 zooplankton, and then gently bubbled it with $\mathrm{N}_{2}$ for five hours to kill any small remaining 143 zooplankton by anoxia. We added $12 x$ concentrated MIII-KS fresh culture medium, to 144 obtain 1x final concentration (see Nicklisch et al. 2008 for detailed composition). After 145 re-aeration we distributed the lake water into $500 \mathrm{~mL}$ transparent incubation bottles 146 (Teflon Fluorinated Ethylene Propylene, Nalgene). These bottles provide the best trade147 off between robustness for incubation in the lake and Photosynthetically Active 
Radiation (PAR [400-700nm]) and Ultra-Violet (UV-A [320-400nm]) transmittance

149 (mean transmittance to PAR $=72 \pm 6.6 \%$; to $\mathrm{UV}-\mathrm{A}=51.4 \pm 3.5 \%$ ).

150

151

152

153 between inocula at the two experimental periods. The species composition of the inocula

154 was very diverse $(n=57$ species) (Appendix -Table 1$)$.

155

156

and vertically moved by a computer-controlled lift in the lake (method described in

157 Köhler et al. 2018). Phytoplankton incubated at constant depth received only the natural

158 sinusoidal diurnal course of sunlight, a treatment that we will refer to as constant light.

159 In contrast, communities incubated in bottles moved vertically through the water

160 column received fluctuating light, by superimposing the vertical light gradient on the

161 natural sinusoidal diurnal sunlight. The lifts simulated a circular movement with 20

162 minutes per revolution, replicating to some extent the full overturn of typical Langmuir

163 cells (Denman and Gargett 1983, Schubert and Forster 1997, Thorpe 2004). We fixed

164 incubation bottles in triplicates at $0,0.2,0.4$ and $0.8 \mathrm{~m}$ depth (constant light treatment).

165 The moving bottles rotated between the water surface $(0 \mathrm{~m})$ and $0.5,1.0$ and $1.8 \mathrm{~m}$ depth 
166 (fluctuating light treatment). The daily PAR values received in both treatments are given

167 in the Appendix (Appendix - Table 2, Fig. 1). Fully dark-adapted subsamples were taken each morning before sunrise. Sample volumes ranged from 80 to $100 \mathrm{~mL}$ to ensure similar total biomass between the different incubation bottles. To avoid nutrient limitation, we refilled the bottles with a mix of filtered lake water (Whatman GF/F glass microfiber) and 12x concentrated MIII-KS fresh

172 culture medium, to obtain $1 \mathrm{x}$ final concentration. The bottles were re-incubated in the 173 lake within 20 minutes.

\section{Abiotic conditions}

176 Global radiation data were measured using a $2 \pi$ light sensor type and were obtained 177 from the NIGLAS monitoring station (TaiHu Laboratory for Lake Ecosystem Research 178 TLLER) located near the experimental site. To obtain daily PAR intensities, we first 179 corrected the global radiation for light attenuation in the lake following the Lambert180 Beer's law:

$$
\mathrm{I}_{\mathrm{z}}=\mathrm{I}_{\mathrm{o}} * \mathrm{e}^{-\mathrm{kz}}
$$

182 where $I_{z}$ is the light intensity at depth $z(\mathrm{~m}), I_{o}$ is PAR at the water surface and $k$ the light 183 attenuation coefficient $\left(\mathrm{m}^{-1}\right)$. The latter was calculated from daily light measurements at $1840.5 \mathrm{~m}$ intervals from the surface to $1.5 \mathrm{~m}$ depth with a spherical spectroradiometer (ASC- 
VIS, TRIOS, Germany). Then, we corrected the light data for shade produced by the pier

(when applicable), for wavelength-specific transmittance of the incubation bottles and

the actual vertical position of the moved phytoplankton.

Vertical profiles of temperature were measured every 5 minutes using temperature loggers (Tinytag, Aquatic 2 TG-4100) sealed to the bottles holders. The lake was very well mixed with temperatures between the lake surface and the bottom differing by less than $0.36^{\circ} \mathrm{C}$ on average during the experimental period.

\section{Cell counts}

194 Species composition was monitored at the beginning, after 2 days and at the end of each 195 of the two experiments. Subsamples were fixed in Lugol's solution (Throndsen 1978).

196 Subsamples taken from each replicate were mixed together to reduce the number of 197 samples to count. Cell abundances of the dominant phytoplankton species were obtained 198 after counting at least 400 algal objects (cell, filament or colony) (Lund et al. 1958) per 199 sample by inverted microscopy (Nikon, Eclipse Ti-S) following the Utermöhl method 200 (Utermöhl 1958). Cell volumes were measured from at least 20 individuals of each 201 species from any sample under the same microscope using Image software. Biovolumes 202 (proxy for phytoplankton biomass) were calculated by multiplying averaged cell 203 volumes by cell abundances. We measured biovolumes for 15 different species: 7 
cyanobacteria, 5 diatoms and 3 chlorophyceae.

\section{Data analysis}

207 The biovolume of a species $i$ relative to the biovolume of the group it belongs to was

208 calculated after 2 days and at the end of both experiments as:

$$
\text { relative biovolume }_{\text {species } \mathrm{i}}=\frac{\text { biovolume }_{\text {species } \mathrm{i}}}{\text { biovolume }_{\text {group }}}
$$

Daily species-specific growth rates $\mu_{i}\left(\right.$ day $\left.^{-1}\right)$ were calculated as follows,

210 accounting for daily dilution:

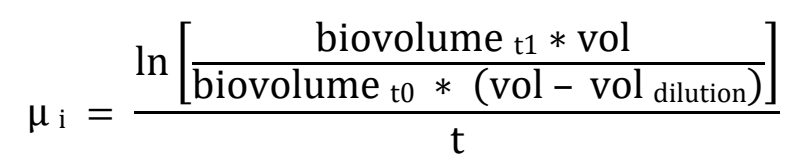

211 with biovolume to and biovolume ${ }_{t 1}$ being the biovolumes of species $i$ at times to and $t 1$.

212 Vol is the total volume of the incubation bottle and vol dilution is the volume sampled for

213 analysis and replaced with fresh culture medium.

To build the growth-light relationships, we fit non-linear mixed effects models to

215 the observed growth rates using the model of Webb et al. 1974:

$$
\mu=\mu_{\max }\left(1-\mathrm{e}^{\frac{-\alpha\left(\mathrm{PAR}-\mathrm{PAR}_{\mathrm{comp}}\right)}{\mu_{\max }}}\right)
$$

216 where $\mu_{\max }$ is the growth rate at saturating light $\left(\mathrm{d}^{-1}\right), \alpha$ is the growth efficiency at

217 limiting light $\left(\mathrm{m}^{2} \mathrm{E}^{-1}\right), P A R_{\text {comp }}$ is the compensation light intensity $\left(\mathrm{E} \mathrm{m}^{-2} \mathrm{~d}^{-1}\right)$ and $P A R$ is 218 the daily PAR exposure $\left(\mathrm{E} \mathrm{m}^{-2} \mathrm{~d}^{-1}\right)$. 
rates measured at day 2 and averaged over [day 2 - end experiment] when plotting

221 growth rates measured at the end of the experiment. We obtained the estimates of the

222 light acquisition traits $\mu_{\max }, \alpha$ and $P A R_{\text {comp }}$ ( \pm standard error) for the best fitting model.

estimations of the effects of light fluctuations on non-equilibrium species coexistence

gradient over more replicates at fewer light intensities. This strategy is in line with the

227 recent call for "regression-based experimental designs" expressing the need to increase

228 the number of predictor levels while decreasing the number of replicates (Cottingham et

229 al. 2005, Beier et al. 2012, de Boeck et al. 2015, Schweiger et al. 2016). Schweiger et al.

230 (2016) recently provided methodological recommendations for such a protocol, arguing

231 that where greater systematic error is likely, such as in field studies, continuous

232 sampling without replication is preferable to sampling fewer but replicated predictor

233 levels along the same gradient.

\section{Realized species niches to daily PAR and mixing depth gradients}

236 In addition to estimating the relative biovolumes of dominant species of cyanobacteria 237 and diatoms over a gradient of daily constant and fluctuating PAR, we also wanted to 
describe the effects of the magnitude of light fluctuations on phytoplankton composition.

239 To this end, we examined species dominance or coexistence regions of diatoms and 240 cyanobacteria over gradients of mixing depths and daily PAR exposure. Traditionally, 241 one would examine the equilibrium phytoplankton growth. But stable growth over time 242 is usually only achievable in laboratory experiments. Given that our study monitored a 243 whole community under natural conditions with diurnal light variation, we cannot 244 expect phytoplankton species to be adapted to a given daily PAR. Thus, we defined 245 regions of "major contribution relative to other species". One species was declared the 246 "winner" over a second species if the difference between their relative biovolumes was > $24710 \%$ (an arbitrary but useful threshold). Species "coexisted" when the variation around 248 their relative biovolumes was $\leq 10 \%$. This approach does not describe steady-state 249 species composition but instead describes the short-term niche partitioning over the 250 daily light supply and mixing depth gradient.

252 coexist in situ through their response to light conditions, because it is in these groups 253 that species are likely to compete more severely for light. Prokaryotes (cyanobacteria) 254 and eukaryotes (diatoms) differ in many aspects of their cellular components, 255 physiology, evolutionary history and acclimatization potential (Glover et al. 1987, 
Gregory 2001, Yoon et al. 2004, Schwaderer et al. 2011) that should promote greater

257 differences in light use between than within groups (Schwaderer et al. 2011).

\section{Statistical analyses}

260 Non-linear mixed effects models were implemented with the $n$ lme R package (Pinheiro et

261 al. 2018 - library nlme R package version 3.1-137) with maximum log likelihood and

262 setting "incubation bottle" as random factor to account for temporal autocorrelation of

263 growth measurements and ensure independence of errors.

Differences in the light acquisition traits $\left(\mu_{\max }, \alpha\right.$ and $\left.P A R_{\text {comp }}\right)$ between constant and fluctuating light were assessed using the non-linear Webb model (Webb et al. 1974)

266 with "incubation bottle" as random factor. We tested the null hypothesis that the light

267 acquisition traits did not vary between constant and fluctuating light, against the

268 alternative hypothesis that one or more traits did vary between treatments. Conclusions

269 on treatment effects were based on model comparisons with F-tests following Bates and

270 Watts (1988, p. 105ff) and providing p-values. The models selected were also supported

271 by the lowest Akaike information criterion (AIC) (Akaike 1974; results not shown). We

272 used the same analytical approach to assess the interspecific differences in the light

273 acquisition traits $\left(\mu_{\max }, \alpha\right.$ and $\left.P A R_{\text {comp }}\right)$ under constant and fluctuating light. Relative

274 species biovolumes along the daily PAR gradient were fit by a logarithmic function 
275 (coefficient * PAR + intercept) using the $n l s($ command. Interspecific differences after two 276 days of experiment were assessed by the same method.

\section{Data deposition}

Data available from

the Dryad

Digital

Repository:

$<\quad$ http://

dx.doi.org/10.5061/dryad.2rh61qk> (Guislain et al. 2018).

\section{Light affinities of dominant species}

285 At all times and in all treatments four taxa, the cyanobacteria Anabaena flos-aquae and

286 Microcystis spp. and the diatoms Aulacoseira granulata and Cyclotella pseudostelligera,

287 dominated the assemblages $(85.3 \pm 9.2 \%$ and $84.3 \pm 4.3 \%$ of the total biovolume under

288 constant and fluctuating light respectively). For convenience we will refer to these

289 phytoplankton taxa by their genus names. Anabaena and Microcystis combined 290 accounted for $25.5 \pm 10.8 \%$ and $24.4 \pm 9.3 \%$ of the total biovolume during the entire 291 experimental period under constant and fluctuating light respectively. Aulacoseira and 292 Cyclotella combined accounted for $59.8 \pm 16.5 \%$ and $59.9 \pm 9.6 \%$ respectively under 
constant and fluctuating light. The contributions of the main phytoplankton groups to the

294 total biovolume are given in the Appendix (Appendix - Table 3).

The contributions of diatoms to the total biovolume tended to slightly decrease with increasing daily PAR supply for the benefit of cyanobacteria (PAR effect not significant; p>0.05) (Appendix - Fig. 2). Chlorophyceae were always very sparse. We noted no differences in the contribution of the main phytoplankton groups (diatoms, cyanobacteria and chlorophyceae) between constant and fluctuating light exposure (all p-values $>0.05$ ). Nevertheless, we observed a strong light dependency of the relative contributions of species within diatoms and cyanobacteria.

Figure 2 depicts species-specific growth-light relationships of the 2 dominant cyanobacteria (Anabaena, Microcystis) and the 2 diatoms (Aulacoseira, Cyclotella) under constant and fluctuating light (see Appendix - Fig. 3 for intraspecific variation). The growth-light relationships of Anabaena and Microcystis intersected under both constant and fluctuating light because of different light affinities of each species to limiting and saturating light. Under constant light (Fig. 2A), Anabaena had slightly higher growth rates at saturating light than did Microcystis, but lower growth rates at limiting light. Under fluctuating light (Fig. 2B) the strategies of both species were reversed with Microcystis having higher growth rates at saturating light than Anabaena, but lower growth rates at limiting light. Amongst the diatoms, Cyclotella always grew far better 
than Aulacoseira at saturating light (Fig. 2C, D). At limiting light, drastic differences in

313 growth rates between species occurred only under mixed conditions, as Aulacoseira 314 grew better than Cyclotella. Estimated values ( \pm standard error) of $\alpha, \mu_{\max }$ and $P A R_{\text {comp }}$ of species dominating

316 the phytoplankton community are presented in Table 1.

317 For cyanobacteria, lower growth rates at limiting light were linked to higher values of 318 PAR comp. Anabaena had significantly higher PAR comp $_{\text {than }}$ Microcystis under constant light $319(\mathrm{p}<0.01)$. The opposite was true under fluctuating light $(\mathrm{p}<0.01)$. Under constant light, 320 Anabaena attained slightly higher $\mu_{\max }$ than Microcystis, but needed a higher $P A R_{\text {comp }}$ than 321 under fluctuating light. Conversely, under fluctuating light, Microcystis had higher $\mu_{\max }$ 322 than Anabaena but needed a significantly higher $P A R_{\text {comp }}$ than under constant light $323(\mathrm{p}<0.001)$. Growth efficiencies $(\alpha)$ did not drive the differences in growth rates between 324 species as Microcystis always had higher $\alpha$ than Anabaena under both light exposures.

325 Note that this trait increased slightly with positive intraspecific variation in $\mu_{\max }$ and $326 P A R_{\text {comp. }}$ Amongst the diatoms, Cyclotella grew significantly faster at saturating light than 328 Aulacoseira under both constant $(\mathrm{p}<0.001)$ and fluctuating $(\mathrm{p}<0.001)$ light (Table 1$)$. In 329 contrast to the cyanobacteria, higher $\mu_{\max }$ of Cyclotella than of Aulacoseira was linked to 330 higher $P A R_{\text {comp }}$ under fluctuating light $(\mathrm{p}<0.001)$ but not under constant light $(\mathrm{p}>0.05)$. 
331 To support the increase of its $\mu_{\max }$ under fluctuating light, Cyclotella needed a 332 significantly higher $P A R_{\text {comp }}(\mathrm{p}<0.001)$ than under constant light. The three light 333 acquisition traits of Aulacoseira slightly increased under constant light ( $\mathrm{p}>0.05)$.

334 As for the cyanobacteria, growth efficiencies $(\alpha)$ did not drive the differences in growth 335 rates between species, as Cyclotella always had higher $\alpha$ than Aulacoseira under both 336 light exposures. Note that this trait also increased with positive intraspecific variations of $337 \mu_{\max }$ and $P A R_{\text {comp }}$. In addition, compensation light intensities of both diatoms were almost 338 always lower and $\alpha$ and $\mu_{\max }$ almost always higher than for the cyanobacteria species.

\section{Relative biovolumes of dominant species over the daily PAR gradient}

341 The relative biovolumes of the two dominant cyanobacteria depended greatly on the

342 daily PAR (Fig. 3A, B) and were significantly different between species (all p343 values $<0.05)$. Similar to the growth-light relationships that were measured in the same 344 species community context, the fits of relative biovolumes intersected (Fig. 3A). 345 Anabaena contributed more at constant saturating light, following its higher $\mu_{\max }$ under 346 such conditions. On the other hand, a lower PAR comp and higher $\alpha$ enabled Microcystis to 347 dominate at constant limiting light. The incubation of the same initial community under fluctuating light reversed, after 2 days only, the relative biovolumes observed under constant light, reflecting the 
changes in light acquisition traits of both species between the two light exposures (Fig.

3B). Microcystis was the saturating light specialist under fluctuating light, increasing its contribution to the assemblage with fluctuating light intensities. Anabaena clearly dominated at fluctuating limiting light following its lower $P A R_{\text {comp }}$ under such conditions. $P A R_{\text {comp }}$ values of the dominant cyanobacteria species clearly determined their relative contributions to the assemblage at limiting light. Microcystis always grew more efficiently (higher $\alpha$ ) than did Anabaena under constant or fluctuating limiting light (Table 1). Yet, Microcystis dominated the assemblage only at constant limiting light (Fig. 3A). Nevertheless, at saturating light under both light treatments, the differences in relative biovolumes of the cyanobacteria were less pronounced (Fig. 3A, B). Note that the differences in light-dependent relative biovolumes were larger after 5 days (not shown because of the time dependence of biovolumes measured after 2 days and at the end of the experiments).

Unlike the cyanobacteria, the relative biovolumes of the diatoms along the gradient of daily PAR followed a similar pattern under both constant and fluctuating light (Fig. 3C, D) and were significantly different between species (all p-values $<0.05$ ). This result reflected the consistency of light affinities between constant and fluctuating light: Cyclotella always had higher $\mu_{\max }$ than Aulacoseira under both constant and fluctuating light (Table 1). Therefore, the contribution of Cyclotella increased with increasing daily 
PAR supply. Differences in relative biovolumes of diatoms were more pronounced under

370 fluctuating light and were described by higher $\mu_{\max }$ and PAR comp of Cyclotella under

371 fluctuating light than under constant light. As for the cyanobacteria, differences in light-

372 dependent relative biovolumes were more pronounced after 5 days (data not shown).

\section{Realized light niches over the daily PAR and mixing depth gradients}

375 Realized light niches of cyanobacteria species were partitioned on both the daily PAR

376 and mixing depth gradients (Fig. 4A). Under stagnant conditions, Microcystis dominated

377 the cyanobacteria biovolume at limiting light whereas Anabaena dominated at saturating

378 light levels above $5 \mathrm{E} \mathrm{m}^{-2} \mathrm{~d}^{-1}$. Under mixing conditions, Anabaena dominated the

379 cyanobacteria assemblage at all investigated daily light intensities when the mixing

380 depth was higher than $0.5 \mathrm{~m}$. Finally, Anabaena and Microcystis equally contributed to

381 the cyanobacteria community roughly at a daily light supply ranging from 2 to $5 \mathrm{E} \mathrm{m}^{-2} \mathrm{~d}^{-1}$

382 under stagnant conditions. Under mixing conditions, both species contributed equally at

383 shallow mixing (0.5 m mixing depth).

384 Unlike the cyanobacteria species, the diatoms maintained consistent light

385 utilization strategies under constant and fluctuating light (Fig. 2C, D and Table 1).

386 Realized niches were thus determined only by the daily PAR gradient (Fig. 4B).

387 Aulacoseira dominated over Cyclotella under stagnant and mixed conditions at low daily 
PAR. In contrast, when the daily PAR supply was greater than roughly $2 \mathrm{E} \mathrm{m}^{-2} \mathrm{~d}^{-1}$,

Cyclotella dominated over Aulacoseira regardless of mixing conditions.

\section{Discussion}

403 driven by the energy allocated to growth (e.g. ribosomes) and light-harvesting 404 machinery (e.g. chlorophyll complexes (Chla:C ratio) and accessory pigments) 405 respectively (Langdon 1988, Klausmeier et al. 2004, Litchman 2007, Talmy et al. 2013). $406 P A R_{\text {comp }}$, the light intensity when $\mu=0$, is driven by the balance between photosynthesis 
407 (and thus, light-harvesting machinery) at limiting light and maintenance respiration 408 (Langdon 1988). PAR comp is primarily affected by maintenance respiratory costs 409 (Langdon 1988). Respiration consumes oxygen in the production of ATP and NADPH to 410 support biosynthesis and cell growth (see Ferris and Christian 1991 for review). As a 411 consequence, the respiration maintenance to growth ratio is higher for high-light 412 acclimated, fast-growing species (high $\mu_{\max }$ ) than for low-light acclimated species. Fast413 growing species achieve compensation levels at higher light intensities and are thus less 414 competitive at limiting light (Geider and Osborne 1989, Geider et al. 1996, Dubinsky and 415 Stambler 2009). Also, excessive photosynthetic excitation may damage the photosystems 416 that could result in additional respiratory costs (Richardson et al. 1983). These light acquisition traits are inherently plastic and their values define the 418 potential of species to grow at certain light supply. The light-saturated growth $\mu_{\max }$ 419 reflects the affinity for saturating light and a species with high $\mu_{\max }$ is considered to be an 420 opportunist, growing faster when light levels increase. On the other hand, a species with 421 high growth efficiency at limiting light $(\alpha)$ and low compensation light intensity 422 (PAR $R_{\text {comp }}$ ) has low light requirements and is considered as gleaner (Grover 1990, 423 Litchman and Klausmeier 2008).

424 Because of the limited energy that can be devoted to the acquisition of a particular 425 resource, physiological trade-offs are expected between the light acquisition traits, such 
as between maximum growth rate (at saturating light) and growth efficiency (at limiting

427 light) (Litchman and Klausmeier 2008). Therefore, one species may outcompete another

428 at saturating or limiting light if its trait value offers a better overall performance. In our

429 study, high $\mu_{\max }$ always (under both constant and fluctuating light) described competitive

430 dominance at saturating light levels. In contrast, species with low PAR comp were more

431 efficient at limiting light and almost always dominated their group biovolume under such

432 conditions. The growth efficiency $(\alpha)$ has been used to characterize the affinity of a

433 species when light is limiting (Schwaderer et al. 2011, Edwards et al. 2013a, 2013b,

434 2015). Our study demonstrates that $P A R_{\text {comp }}$ was the most relevant trait related to the

435 ability of a species to outcompete others under constant and fluctuating limiting light

436 supply. According to our results, the dominant species at limiting light was almost

437 always the one with the lowest $P A R_{\text {comp }}$ value, regardless of $\alpha$. We expect that this may

438 result from the short duration of our experiment as maintenance costs, such as

439 photoprotection mechanisms (influencing $P A R_{\text {comp }}$ ) could act at shorter timescales than

440 growth (determined by $\alpha$ at limiting light) (Falkowski 1984, Ferris and Christian 1991,

441 MacIntyre et al. 2000). By measuring the species dominance patterns after only couple of

442 days, we increased the relative importance of short-term mechanisms and likely

443 favoured species with low $P A R_{\text {comp }}$ rather than high $\alpha$ under limiting light. It is likely that

$444 \alpha$ values could have had greater impact on competitive outcomes at limiting light on 
445 longer timescales. However, longer periods of constant conditions rarely occur in 446 dynamic systems.

447 Overall, the short-term gleaner-opportunist trade-off exhibited by species in our study 448 seemed to be driven by the enhancement of photosynthesis that increases slightly $\alpha$, and 449 to a much larger extent $\mu_{\max }$-increasing de facto the maintenance respiratory costs $450\left(P A R_{\text {comp }}\right)$. Nevertheless, under more stable conditions (such as in the laboratory) and at 451 longer time scale, it is likely that the gleaner-opportunist trade-off is mostly driven by 452 the balance between resource allocation to growth machinery (e.g. ribosomes) at 453 saturating light (affecting $\mu_{\max }$ ) and allocation to light-harvesting machinery (e.g. 454 chlorophyll complexes) at limiting light (affecting $\alpha$ ). Different light acquisition traits will cause big changes in species biovolumes only 456 in the long run. After very few days of new conditions, the now better acclimated species 457 will not necessarily already dominate the group/community. All the dominant species 458 were probably well adapted to the lake conditions prior to our sampling. This could be 459 explained by the assumption of variable conditions in such wind-exposed shallow lake, 460 covering both stagnant and mixing periods. 
There is a great deal of evidence that interspecific variation in light acquisition traits plays a role in maintaining species diversity through niche partitioning in communities

465 (Litchman and Klausmeier 2001, Schwaderer et al. 2011, Adler et al. 2013). In a stratified 466 eutrophic lake, phytoplankton must cope mostly with spatial heterogeneity in light 467 intensity that declines exponentially with depth. Phytoplankton at the surface receives 468 saturating light, but exclusively on days with little cloud cover. At deeper layers, light 469 availability limits phytoplankton growth. Light availability is also limiting if scums of buoyant colonies / floating macrophytes shade lower depths or colonies self-shade the 471 inner cells. In our study, we mimicked calm thermally stratified conditions by incubating 472 phytoplankton at fixed depths in the lake. The growth-light relationships of Anabaena and Microcystis under constant light 474 intersected over the daily PAR gradient. The species displayed different light affinities to 475 limiting and saturating light, thereby exhibiting a gleaner-opportunist trade-off (Grover 476 1990). As the gleaner (high $\alpha$ and low $P A R_{\text {comp }}$ ), Microcystis grew more efficiently at 477 limiting light and dominated under constant limiting light. As the opportunist (high $\mu_{\max }$ ), 478 Anabaena grew better under saturating light and contributed more to the cyanobacteria 479 biovolume with increasing daily PAR. These alternative light utilization strategies 480 exhibited after only couple of days allowed coexistence of these species on a gradient of 481 constant PAR while avoiding competitive exclusion. Previous studies also identified the 
importance of the gleaner-opportunist trade-off for species coexistence along the PAR gradient (Litchman and Klausmeier 2001). Ultimately our results confirmed that 484 opportunist species (high $\mu_{\max }$ ) are more likely to thrive under saturating light, especially 485 when high losses (e.g. by predation) limit self-shading. In contrast, gleaner species (high 486 $\alpha$, low $P A R_{\text {comp }}$ ) are more competitive in highly productive/turbid systems when light 487 levels are low. The gleaner-opportunist trade-off was not evident amongst the dominant diatom species. While Cyclotella had higher $\mu_{\max }$ and $\alpha$ than Aulacoseira, their PAR comp were 490 similar. Meta-analyses of growth-light experiments on marine diatoms species (Edwards et al. 2015) indicate a positive correlation between $\mu_{\max }$ and $\alpha$. High values in both 492 maximal growth rates and growth efficiency at limiting light likely evolved by allowing 493 diatoms to survive in turbulent systems where they are usually present and where PAR 494 fluctuates between high and low intensities. This evolutionary hard-wiring in the growth 495 traits is apparently still expressed under constant light conditions in our experiment. 496 Interspecific differences in $\mu_{\max }$ values between diatoms explained why Cyclotella 497 contributed more to the biovolume of diatoms with increasing daily PAR. In contrast, the 498 dominance of Aulacoseira at limiting light is not explainable by light traits (lower growth 499 efficiency and similar $\left.P A R_{\text {comp }}\right)$. Traits like affinity for nutrients or vulnerability for 500 grazing were excluded in our experiment but act under natural conditions. There, the 
501 unicellular Cyclotella should suffer from higher grazing losses than the filamentous 502 Aulacoseira. This might explain the higher biomass of Aulacoseira than of Cyclotella in the 503 inocula, which were assembled from the natural system. Our experiment was likely too 504 short to enable drastic changes in relative species biomass at low light where absolute 505 growth rates of both species were low. In the long run, Cyclotella should outcompete 506 Aulacoseira at all light intensities if our incubation conditions (replete nutrients, low 507 grazing pressure, no sedimentation) are provided. Our results confirm generally, that under semi-natural conditions, interspecific

509 variation of light acquisition traits can reduce niche overlap within few days thereby 510 precluding competitive exclusion in a spatially heterogeneous light climate. As a 511 consequence, species diversity within the same phytoplankton group is maintained 512 owing to the PAR gradient occurring in the lake. Nevertheless, such constant light 513 conditions would rarely occur in well-mixed water layers.

\section{Effects of fluctuating light under vertical mixing}

516 Under semi-natural conditions, temporal light fluctuations may result in differences in 517 light acquisition parameters of phytoplankton communities incubated either under 518 constant or fluctuating light (Köhler et al. 2018). However, it is still unknown how the species-specific variation in light acquisition traits may affect the coexistence in situ. 
Thus, it is critical to estimate light acquisition traits under fluctuating light conditions to

521 explain the development of phytoplankton at vertical mixing. Under fluctuating light conditions, phytoplankton must cope with light

523 heterogeneity that is both spatial (in the water column) and temporal (in our study,

524 diurnal course of light +20 minute fluctuations). Hence, phytoplankton must be

525 acclimated to both mean level and dynamics of light intensity as they have to cope with

526 the probability of the different light intensities and with the speed of changes. Forecasts

527 of phytoplankton development in situ are uncertain if based on growth-light

528 relationships measured under constant light because mean intensity as well as dynamic

529 of light availability may co-limit growth. Indeed, our results showed that strong

530 intraspecific variation in light acquisition traits under constant and fluctuating light

531 affected competitive outcomes.

As was the case for constant light exposure, the cyanobacteria displayed a

533 gleaner-opportunist trade-off also under fluctuating light. However, the dominant

534 species switched their strategies and dominance patterns: Microcystis, gleaner under

535 constant light became opportunist (high $\mu_{\max }$ ) under fluctuating light while Anabaena,

536 opportunist under constant light became a gleaner (low $P A R_{\text {comp }}$ ) under fluctuating light.

537 This intraspecific variation indicates a strong and fast plasticity of cyanobacteria light 538 acquisition traits, explaining the observed changes in relative biovolumes of dominant 
species after only two days. The reduction of the minimal light requirements of

540 Anabaena flos-aquae under fluctuating light (4h high:4h low light) compared to constant

541 light has been hypothesized to be one of the reasons of the increased coexistence

542 potential with another cyanobacteria (the filamentous Phormidium luridum var.) in the

543 laboratory by Litchman (2003).

544 In contrast, light utilization strategies of diatoms were not reversed and the

545 competitive outcomes remained similar. Again, these results indicate the strong

546 adaptation of diatoms to vertical mixing (Reynolds 2006). It is also worth noting that

547 diatoms had overall higher growth rates than cyanobacteria. Nevertheless, because of

548 their relatively small size and high density, diatoms must cope with higher losses by

549 sedimentation and grazing. Therefore, in nature, diatoms may attain a lower biomass

550 than cyanobacteria despite faster gross growth.

With increasing $\mu_{\max }$, or higher affinity to saturating light, $\alpha$ of both diatoms and

552 cyanobacteria species increased slightly. Such phenomenon could be explained by

553 photosynthesis enhancement whereby opportunists benefit from intermittent saturating

554 light peaks at the water surface to optimize performance (Marra 1978, Kana and Glibert

555 1987), but which negatively influences their ability to grow at limiting light levels

556 because of increasing maintenance metabolic cost (Richardson et al. 1983). 


\section{Realized light niches over the daily PAR and mixing depth gradients}

559 One of the main challenges in community ecology is to understand how environmental

560 variability shapes the community composition and dynamics in situ (Chesson 2000,

561 Adler et al. 2013). We observed that inter- and intraspecific variation in light acquisition

562 traits toward both mean level and dynamics of light intensity enhanced species

563 coexistence over the PAR gradient. Yet the daily PAR received by phytoplankton in lakes

564 depends, amongst other factors, on the surface irradiance and the mixing depth, the

565 latter being inversely related to the daily PAR.

566 Diatoms displayed the more straightforward scenario. As mixing specialists,

567 diatoms did not modify their light utilization strategies between constant and fluctuating

568 light regimes. The opportunist Cyclotella dominated the diatom biovolume along the

569 whole mixing gradient at saturating light, while Aulacoseira did so along the whole

570 mixing gradient at limiting light. Under mixing conditions, the dominance of Aulacoseira

571 over Cyclotella was favoured by its lower compensation light intensity. Their relative

572 contributions along the gradient of fluctuating light regimes were very distinct after 2

573 days (Fig. 3D) and amplified after 5 days of incubation under both light exposures (Fig

574 4B). Thus, no region of similar contribution appeared on the daily PAR $\mathrm{x}$ mixing depth

575 gradients. However, these results are not fully transferable to natural conditions. Our

576 incubations avoided losses by sedimentation and largely grazing. Under calm conditions, 
sedimentation should affect the larger Aulacoseira more strongly than the single-celled

578 Cyclotella. In contrast, the latter is more vulnerable to grazing.

580

581

582

dim layers of a non-mixed lake is unlikely. Instead, we assume that variation in available

584 light is driven solely by changing cloud cover and light distribution within the colonies.

585 Unlike the diatoms, the cyanobacteria species had similar relative biomasses across a

586 large range of light intensities (from 2 to $5 \mathrm{E} \mathrm{m}^{-2} \mathrm{~d}^{-1}$ ) under both constant and fluctuating

587 light exposure (Fig. 4A). This phenomenon might be, at least partly, explained by self-

588 shading inside of colonies which is poorly understood so far. Nonetheless, it is

589 conceivable that the development of the colonial cyanobacterial opportunist allowed the

590 gleaner to develop because of the limiting effects of self-shading in the colony. On the

591 other hand, at limiting light levels, only the gleaner with very low light requirements

592 could thrive. This explains the observed higher differences in growth rates and relative

593 biovolumes of species at limiting than at saturating light. Thus, cyanobacteria species

594 may coexist under both stable and mixing conditions at sub-saturating irradiances, and a

595 drastic increase or decrease of the daily PAR may quickly favour the opportunist or 
596 gleaner species respectively. Cyanobacteria were affected by vertical mixing with 597 Anabaena and Microcystis switching light utilization strategies, resulting in a niche 598 partitioning along gradients of daily PAR and mixing depth. The gleaner Anabaena 599 benefited from vertical mixing deeper than $0.5 \mathrm{~m}$ when the daily PAR was low, and from 600 its higher initial biovolume. Microcystis could not outcompete the latter because of its 601 high compensation light intensity under fluctuating light. However, at shallow mixing 602 depths (below $0.5 \mathrm{~m}$ deep) a region of similar contribution existed owing to lower 603 interspecific differences in absolute growth rates at saturating than at limiting light.

604 Our study points to the mechanistic linkages between more natural light 605 environment and phytoplankton dynamics in Lake TaiHu. That said, our goal was not to 606 forecast the development of phytoplankton communities in this particular lake under 607 mixed or stratified conditions. We investigated only one frequency of light fluctuation 608 (20 minutes) and the light dynamics within the lake itself will be more stochastic, 609 operating at different temporal scales. The observed light-dependency of growth is 610 caused by physiological mechanisms which act at different time scales. However, our 611 experiment resembled natural conditions much better than any approach that neglects 612 light dynamics or species interactions. We advocate approaches that target the variation 613 in light acquisition traits under constant and fluctuating light directly as these may 614 counter predictions made on a species-by-species basis. 


\section{Conclusions}

617 High biodiversity of natural phytoplankton communities has been attributed primarily to

618 eco-evolutionary responses of phytoplankton groups to different levels of constant light

619 exposure (i.e. variation across depth only). Our study demonstrates under semi-natural

620 conditions the existence of interspecific variation in light affinities allowing the

621 coexistence of species with different light utilization strategies in spatially

622 heterogeneous light conditions. In addition, the overlooked intraspecific variation in

623 light acquisition traits under fluctuating light impacted the community composition. We

624 demonstrated for the first time that vertical mixing may alter, or even reverse, light

625 utilization strategies of phytoplankton species. Non-equilibrium conditions increase the

626 amount of niches where acclimated species may thrive, allowing coexistence and

627 avoiding competitive exclusion even in seemingly homogeneous environments. 
Acknowledgments - We thank Thomas Mehner and the participants of the workshop "Scientific Writing" at the Leibniz-Institute of Freshwater Ecology and Inland Fisheries for helpful discussions on an early stage of the manuscript. We acknowledge Katrin Preuß for the species determination, Wenhao Ding for logistic help during our experiment, Tom Shatwell, Kate Laskowski and Ramsy Agha for help with the statistics and Nicolas Guislain for graphic support. Facilities were provided by the Nanjing Institute of Geography and Limnology and Chinese Academy of Sciences. We thank Pr. Qin for offering these facilities. Finally, we acknowledge the editors and an anonymous reviewer for valuable comments on the manuscript.

Funding - This work is part of the Sino-German water supply project SIGN funded by the German Ministry of Education and Research (Grant number 02WCL1336D to AG and JK). BEB acknowledges funding from the Humboldt Foundation for supporting her temporary stay at the IGB in Germany.

\section{Declarations}

The authors declare no conflict of interest 
Adler, P. B. et al. 2013. Trait-based tests of coexistence mechanisms. - Ecol. Lett. 16: 1294-1306.

Akaike, H. 1974. A new look at the statistical model identification. - IEEE transactions on automatic control 19: 716-723.

Amarasekare, P. 2003. Competitive coexistence in spatially structured environments: A synthesis. - Ecol. Lett. 6: 1109-1122.

Avendaño-Coletta, D. and Schubert, H. 2005. Oxygen evolution and respiration of the cyanobacterium Synechocystis sp PCC 6803 under two different light regimes applying light/dark intervals in the time scale of minutes. - Physiol Plant 125: 381391.

Bates, D. M. and Watts, D. G. 1988. Nonlinear Regression Analysis and its Applications. Wiley.

Beier, C. et al. 2012. Precipitation manipulation experiments - challenges and recommendations for the future. - Ecol. Lett. 15: 899-911.

Beisner, B. E. 2001. Plankton community structure in fluctuating environments and the role of productivity. - Oikos 95: 496-510. 
Chesson, P.L. and Case, T.J. 1986. Overview: nonequilibrium community theories: chance, variability, history, and coexistence. - Community Ecology: 229-239 (ed. J. Diamond and T.J. Case). Harper and Row, New York.

Chesson, P. 2000. Mechanisms of maintenance of species diversity. - Annual Review of Ecology and Systematics 31: 343-366.

Cottingham, K. L. et al. 2005. Knowing when to draw the line: designing more informative ecological experiments. - Front. Ecol. Environ. 3: 145-152.

de Boeck, H. J. et al. 2015. Global Change Experiments: Challenges and Opportunities. Bioscience 65: 922-931.

Denman, K. L. and Gargett, A. E. 1983. Time and space scales of vertical mixing and advection of phytoplankton in the upper ocean. - Limnol. Oceanogr. 28: 801-815.

Duan, H. et al. 2009. Two-Decade Reconstruction of Algal Blooms in China's Lake TaiHu. Environ. Sci. Technol. 43: 3522-3528.

Dubinsky, Z. and Stambler, N. 2009. Photoacclimation processes in phytoplankton: mechanisms, consequences, and applications. - Aquat. Microb. Ecol. 56: 163-176.

Edwards, K. F. et al. 2013a. Functional traits explain phytoplankton community structure and seasonal dynamics in a marine ecosystem. - Ecol. Lett. 16: 56-63. 
Edwards, K. F. et al. 2013b. Functional traits explain phytoplankton responses to environmental gradients across lakes of the United States. - Ecology 94: 16261635.

Edwards, K. F. et al. 2015. Light and growth in marine phytoplankton: allometric, taxonomic, and environmental variation. - Limnol. Oceanogr. 60: 540-552.

Falkowski, P. G. 1984. Physiological responses of phytoplankton to natural light regimes. - J. Plankton Res. 6: 295-307.

Falkowski, P. G. et al. 1998. Biogeochemical controls and feedbacks on ocean primary production. - Science 281: 200-206.

Ferris, J. M. and Christian, R. 1991. Aquatic primary production in relation to microbial responses to changing light: A review. - Aquat. Sci. 53: 187-217.

Field, C. B. et al. 1998. Primary Production of the Biosphere: Integrating Terrestrial and Oceanic Components. - Science 281: 237-240.

Fietz, S. and Nicklisch, A. 2002. Acclimation of the diatom Stephanodiscus neoastraea and the cyanobacterium Planktothrix agardhii to simulated natural light fluctuations. Photosynth. Res. 72: 95-106.

Flöder, S. et al. 2002. The influence of fluctuating light intensities on species composition and diversity of natural phytoplankton communities. - Oecologia 133: 395-401.

Geider, R. J. and Osborne, B. A. 1989. Respiration and microalgal growth: a review of the 
quantitative relationship between dark respiration and growth. - New Phytol. 112: $327-341$.

Geider, R. J. et al. 1996. A dynamic model of photoadaptation in phytoplankton. - Limnol. Oceanogr. 41: 1-15.

Glover, H. E. et al. 1987. The effects of light quality and intensity on photosynthesis and growth of marine eukaryotic and prokaryotic phytoplankton clones. - J. Exp. Mar. Bio. Ecol. 105: 137-159.

Gregory, T. R. 2001. Coincidence, coevolution, or causation? DNA content, cell size, and the C - value enigma. - Biol. Rev. 76: 65-101.

Grover, J.P. 1990. Resource Competition in a Variable Environment: Phytoplankton Growing According to Monod 's model. - Am. Nat. 136: 771-789.

Guislain, A. et al. 2018. Data from: variation in species light acquisition traits under fluctuating light regimes: implications for non-equilibrium coexistence. - Dryad Digital Repository, <http://dx.doi.org/10.5061/dryad.2rh61qk>.

Havelková-Doušová, H. et al. 2004. Photoacclimation of Dunaliella tertiolecta (Chlorophyceae) under fluctuating irradiance. - Photosynthetica 42: 273-281.

Hutchinson, G.E. 1961. The paradox of the plankton. - Am. Nat. 95: 137-145. 
Kana, T. M., and Glibert. P. M. 1987. Effect of irradiances up to $2000 \mu \mathrm{E} / \mathrm{m}^{2} \mathrm{~s}$ on marine Synechococcus Wh7803. 2. Photosynthetic response and mechanisms. - Deep-Sea Res. Part A Oceanogr. Res. Pap. 34: 497-516.

Kardinaal, W. E. A. et al. 2007. Competition for light between toxic and nontoxic strains of the harmful cyanobacterium Microcystis. - Appl. Environ. Microbiol. 73: 2939-2946.

Klausmeier, C. A. et al. 2004. Optimal nitrogen-to-phosphorous stoichiometry of phytoplankton. - Nature 429: 171-174.

Köhler, J. et al. 2018. Influence of vertical mixing on light-dependency of phytoplankton growth. - Limnol. Oceanogr. 63: 1156-1167.

Koussoroplis, A. M. et al. 2017. Understanding and predicting physiological performance of organisms in fluctuating and multifactorial environments. - Ecol. Monogr. 87: 178-197.

Langdon, C. 1988. On the Causes of Interspecific Differences in the Growth Irradiance Relationship for Phytoplankton. II. A General-Review. - J. Plankton Res. 10: 12911312.

Lawrence, D. et al. 2012. Species interactions alter evolutionary responses to a novel environment. - PLoS Biol. 10.5: e1001330.

Litchman, E. 1998. Population and community responses of phytoplankton to fluctuating light. - Oecologia 117: 247-257. 
Litchman, E. and Klausmeier, C. A. 2001. Competition of phytoplankton under fluctuating light. - Am. Nat. 157: 170-187.

Litchman, E. 2003. Competition and coexistence of phytoplankton under fluctuating light: Experiments with two cyanobacteria. - Aquat. Microb. Ecol. 31: 241-248.

Litchman, E. 2007. Resource competition and the ecological success of phytoplankton. Edited by Falkowski, P.G. and Knoll, A. 2007. - Evol. Prim. Prod. Sea: p. 351-375.

Litchman, E. and Klausmeier, C. A. 2008. Trait-based community ecology of phytoplankton. - Annu. Rev. Ecol. Evol. Syst. 39: 615-639.

Litchman, E. et al. 2012. Phytoplankton niches, traits and eco-evolutionary responses to global environmental change. - Mar. Ecol. Prog. Ser. 470: 235-248.

Litchman, E. et al. 2015. Global biogeochemical impacts of phytoplankton: A trait-based perspective. - J. Ecol. 103: 1384-1396.

Lund, J. W. G. et al. 1958. The inverted microscope method of estimating algal numbers and the statistical basis of estimations by counting. - Hydrobiologia 11: 143-170.

MacIntyre, H. L. et al. 2000. The effect of water motion on short-term rates of photosynthesis by marine phytoplankton. - Trends Plant Sci. 5: 12-17.

Marra, J. 1978. Phytoplankton photosynthetic response to vertical movement in a mixed layer. - Mar. Biol. 46: 203-208. 
Nicklisch, A. 1998. Growth and light absorption of some planktonic cyanobacteria, diatoms and Chlorophyceae under simulated natural light fluctuations. - J. Plankton Res. 20: 105-119.

Nicklisch, A. et al. 2008. Analysis and modelling of the interactive effects of temperature and light on phytoplankton growth and relevance for the spring bloom. - J. Plankton Res. 30: 75-91.

Pinheiro, J. et al. 2018. nlme: Linear and Nonlinear Mixed Effects Models. R package version 3.1-137, <URL : https://CRAN.R-project.org/package=nlme>.

Qin, B. et al. 2010. A drinking water crisis in Lake TaiHu, China: Linkage to climatic variability and lake management. - Environ. Manage. 45: 105-112.

R Core Team. 2016. R: A language and environment for statistical computing. R Foundation for Statistical Computing, Vienna, Austria.

Reynolds, C. S. 2006. The Ecology of Phytoplankton. Cambridge University Press.

Richardson, K. et al. 1983. Adaption of unicellular algae to irradiance: an analysis of strategies. - New Phytol. 93: 157-191.

Schubert, H. and Forster, R. M. 1997. Sources of variability in the factors used for modelling primary productivity in eutrophic waters. - Hydrobiologia 349: 75-85.

Schwaderer, A. S. et al. 2011. Eco-evolutionary differences in light utilization traits and distributions of freshwater phytoplankton. - Limnol. Oceanogr. 56: 589-598. 
Schweiger, A. H. et al. 2016. Optimizing sampling approaches along ecological gradients. - Methods Ecol. Evol. 7: 463-471.

Shatwell, T. et al. 2012. Temperature and photoperiod effects on phytoplankton growing under simulated mixed layer light fluctuations. - Limnol. Oceanogr. 57: 541-553.

Silvertown, J. 2004. Plant coexistence and the niche. - Trends Ecol. Evol. 19: 605-611.

Sommer, U. 1984. The paradox of the plankton: Fluctuations of phosphorus availability maintain diversity of phytoplankton in flow-through cultures. - Limnol. Oceanogr. 29: $633-636$.

Sommer, U. 1985. Comparison between steady state and non-steady state competition: Experiments with natural phytoplankton. - Limnol. Oceanogr. 30: 335-346.

Talmy, D. et al. 2013. An optimality model of photoadaptation in contrasting aquatic light regimes. - Limnol. Oceanogr. 58: 1802-1818.

Thorpe, S.A. 2004. Langmuir circulation. - Annu. Rev. Fluid Mech. 36: 55-79.

Throndsen, J. 1978. Preservation and storage. Phytoplankton manual.

Utermöhl, H. 1958. Zur Vervollkommnung der quantitativen Phytoplankton-Methodik. Mit. Int. Ver. Theo. Angew. Limnol. 9: 1-38.

Yoon, H. S. et al. 2004. A Molecular Timeline for the Origin of Photosynthetic Eukaryotes. - Mol. Biol. Evol. 21: 809-818. 
Webb, W. L. et al. 1974. Carbon dioxide exchange of Alnus rubra: A mathematical model. - Oecologia 17: 281-291. 
Table 1. Calculated light acquisition traits $\alpha, \mu_{\max }$ and $P A R_{c o m p}$ (estimate \pm standard error) of the four dominant species under A) constant and B) fluctuating light. The goodness of fit is also presented for each trait in brackets. Units: $\mu_{\max }$ in $\mathrm{d}^{-1}, \alpha$ in $\mathrm{m}^{2} \mathrm{E}^{-1}$ and $P A R_{\text {comp }}$ in $\mathrm{E} \mathrm{m}^{-2} \mathrm{~d}^{-1}$.

\begin{tabular}{ccccc} 
A & Anabaena & Microcystis & Aulacoseira & Cyclotella \\
\hline$\mu_{\max }$ & $0.32 \pm 0.18(0.11)$ & $0.25 \pm 0.08<0.05$ & $0.48 \pm 0.11<0.01$ & $1.16 \pm 0.16<0.001$ \\
$a$ & $0.31 \pm 0.12<0.05$ & $0.52 \pm 0.25(0.08)$ & $0.71 \pm 0.43(0.15)$ & $0.88 \pm 0.30<0.05$ \\
$P A R_{\text {comp }}$ & $1.60 \pm 0.39<0.01$ & $0.65 \pm 0.23<0.05$ & $0.44 \pm 0.20(0.08)$ & $0.16 \pm 0.12(0.25)$ \\
& & & & \\
B & & & & \\
\hline$\mu_{\max }$ & $0.18 \pm 0.08(0.08)$ & $0.32 \pm 0.20(0.19)$ & $0.40 \pm 0.07<0.05$ & $1.69 \pm 0.84(0.09)$ \\
$a$ & $0.24 \pm 0.27(0.43)$ & $0.60 \pm 0.23(0.06)$ & $0.44 \pm 0.17(0.08)$ & $0.94 \pm 0.29<0.05$ \\
$P A R_{\text {comp }}$ & $0.76 \pm 0.87(0.43)$ & $1.54 \pm 0.22<0.01$ & Set to 0 & $1.27 \pm 0.13<0.001$ \\
\hline
\end{tabular}




\section{Figure Legend}

Figure 1. Graphical description of the light acquisition traits $\alpha, \mu_{\max }$ and $P A R_{\text {comp }}$

Figure 2. Species-specific growth-light relationships of the two dominant cyanobacteria (Anabaena, Microcystis) under A) constant and B) fluctuating light; and the two dominant diatoms (Cyclotella, Aulacoseira) under C) constant and D) fluctuating light.

Figure 3. Light-dependency of the relative biovolumes of Anabaena and Microcystis to the cyanobacteria biovolume (A, B) and of Cyclotella and Aulacoseira to the biovolume of diatoms (C, D) under constant (A, C) and fluctuating light (B, D). Only relative biovolumes after 2 days of experiment are depicted.

Figure 4. Realized niches of the A) cyanobacteria and B) diatoms after 2 days and at the end of the experiments (crossed symbols) over gradients of daily PAR exposure (E m-2 $\mathrm{d}^{-1}$ ) and mixing depth (m). 


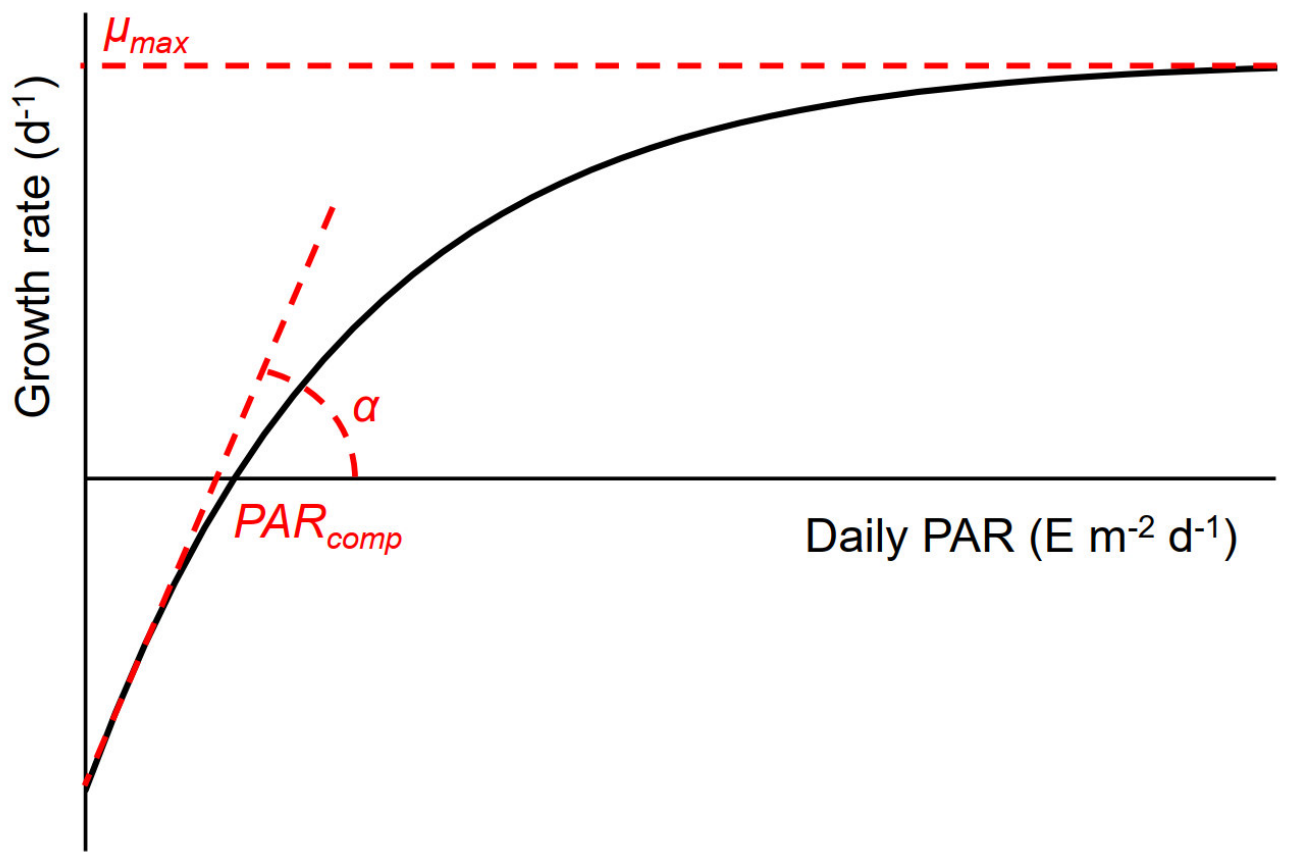

Figure 1 


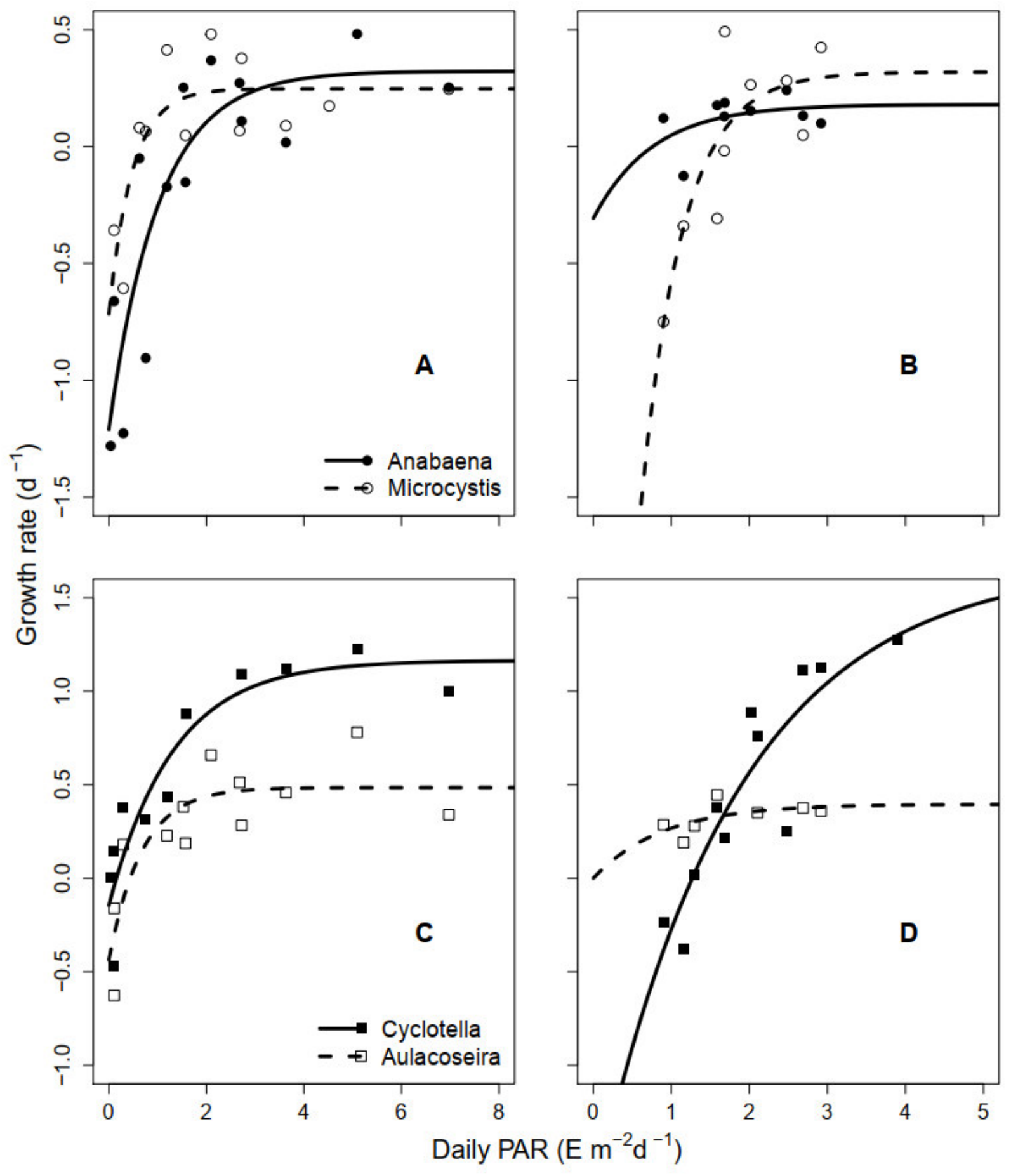

Figure 2 


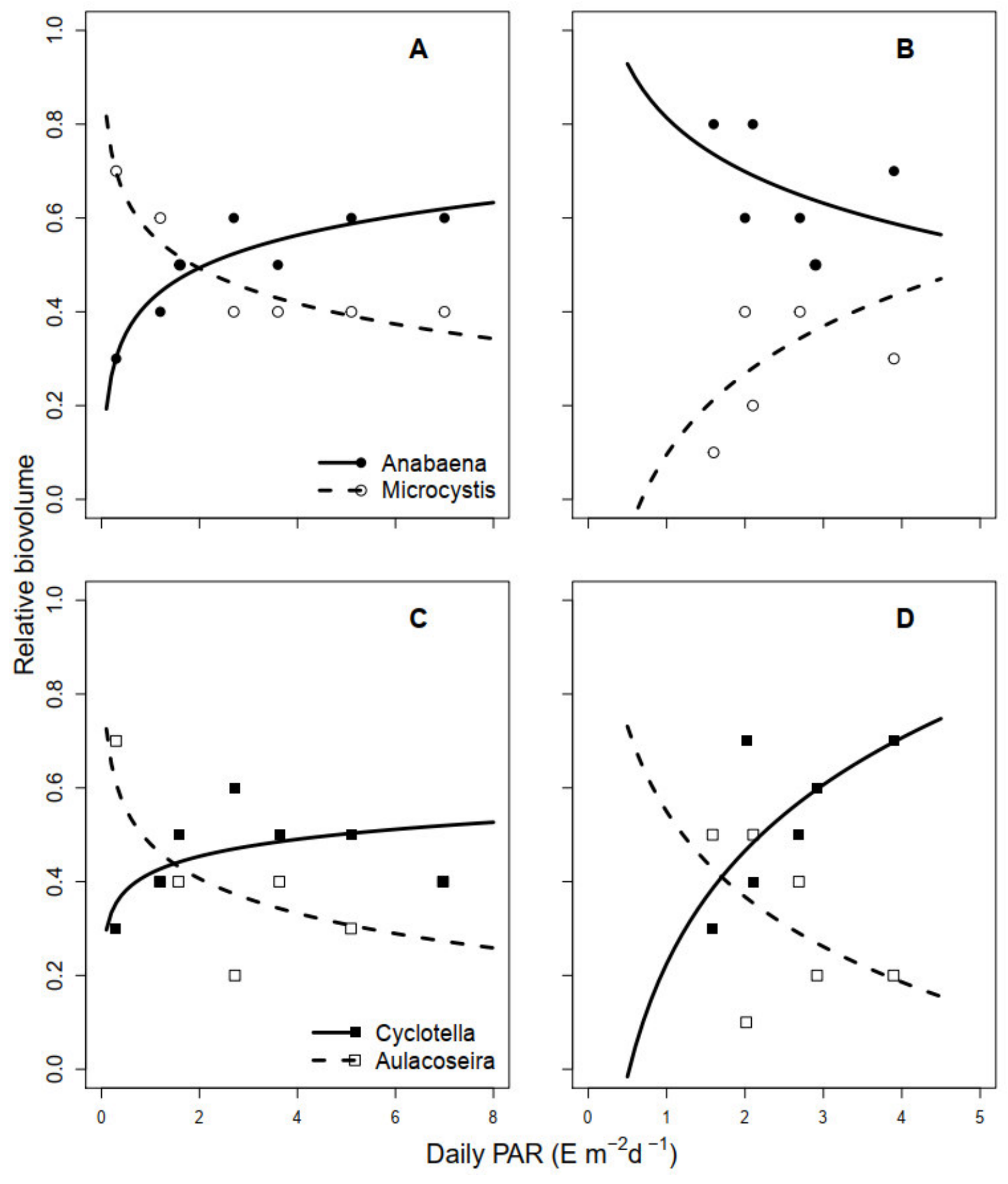

Figure 3 


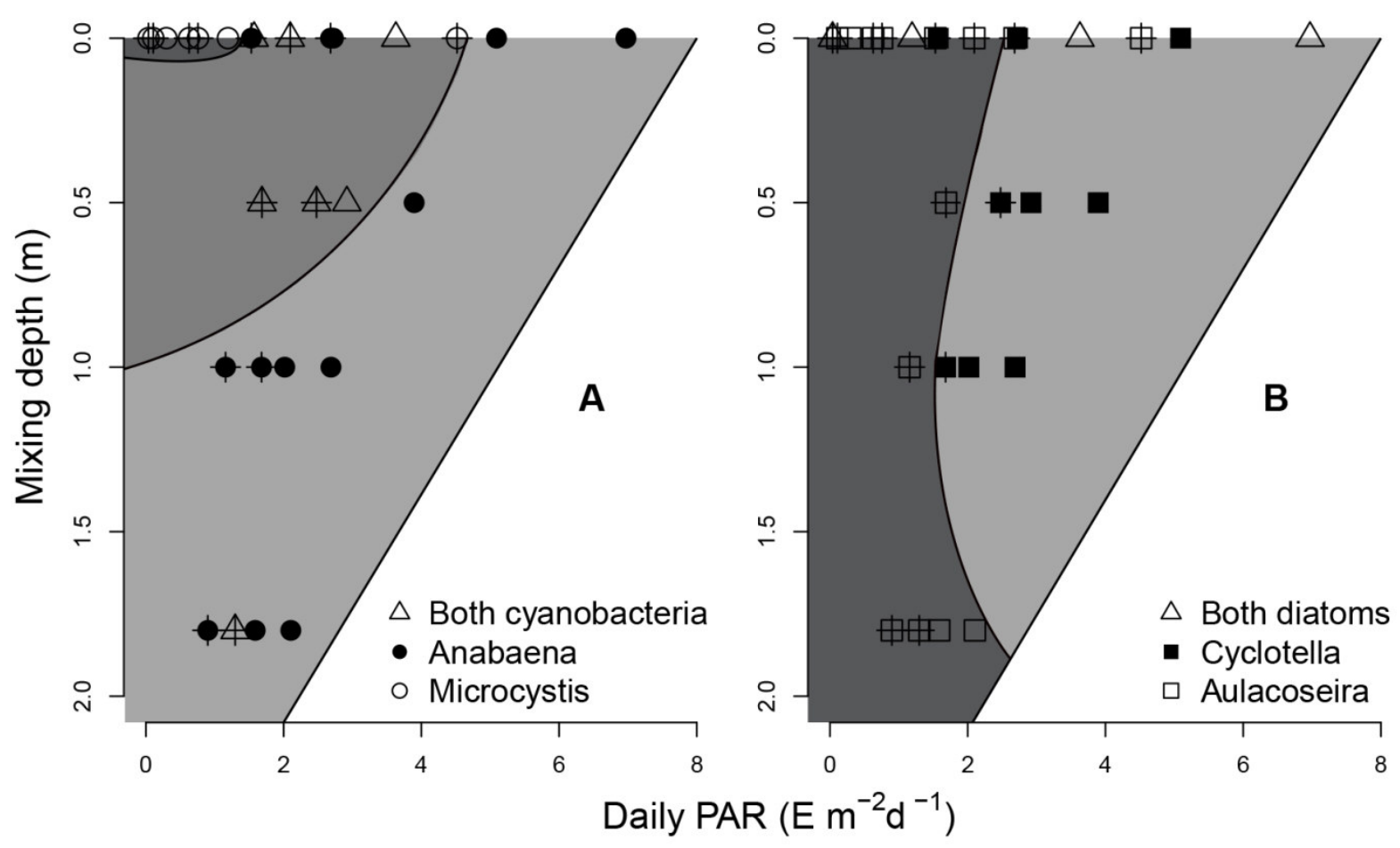

Figure 4 
Appendix-Table 1. Species composition of the isolated Lake TaiHu phytoplankton community during the experiment. Chloro: Chlorophyceae; Bacill: Bacillariophyceae; Cyano: Cyanophyceae; Zygn: Zygnematophyceae.

\begin{tabular}{ll}
\hline Class & Species \\
\hline Chloro & Actinastrum hantzschii \\
- & Coelastrum astroideum \\
- & Coelastrum microporum \\
- & Crucigenia fenestrata \\
- & Crucigenia quadrata \\
- & Crucigeniella apiculata \\
- & Didymocystis spec. \\
- & Elakatothrix spec. \\
- & Eudorina spec. \\
- & Lagerheimia ciliata \\
- & Lagerheimia wratislavensis \\
- & Micractinium pusillum \\
- & Monoraphidium arcuatum \\
- & Monoraphidium contortum \\
- & Monoraphidium griffithii \\
- & Oosystis spp. \\
- & Pediastrum boryanum \\
- & Pediastrum duplex \\
- & Pediastrum simplex \\
- & Pediastrum tetras \\
- & Planktonema (Binuk.) lauterbornii \\
- & Planktosphaeria gelatinosa \\
- & Raphidocelis spec. \\
- & Scenedesmus acuminatus \\
- & Scenedesmus bijuga \\
- & Scenedesmus communis \\
- & Scenedesmus falcatus \\
- & Scenedesmus intermedius \\
- & Scenedesmus maximus \\
- & Scenedesmus sempervirens \\
- & Scenedesmus serratus \\
- & Scenedesmus subspicatus \\
- & Scenedesnus spp \\
- & Schroederia indica \\
- & Schroederia setigera \\
- & Schroederia spec. \\
- & Tetraedron caudatum \\
\hline & \\
\hline
\end{tabular}

\begin{tabular}{ll}
\hline Bacill & Aulacoseira granulata \\
- & Aulacoseira spp. \\
- & Cyclotella pseudostelligera \\
- & Nitzschia acicularis \\
- & Nitzschia fonticola \\
- & Nitzschia spp. \\
\hline Cyano & Anabaena flos- aquae \\
- & Anabaena spec., gerade \\
- & Aphanizomenon issatschenkoi \\
- & Chroococcus turgidus \\
- & Geitlerinema unsure \\
- & Limnothrix spec. \\
- & Merismopedia spec \\
- & Microcystis spec. \\
- & Oscillatoria spp. \\
- & Planktothrix spp \\
- & Raphidiopsis curvata \\
- & Raphidiopsis spec. \\
\hline Zygn & Closterium acutum v. variabile \\
\hline
\end{tabular}


Appendix-Table 2. Daily photosynthetically active radiation $\left(\mathrm{E} \mathrm{m}^{-2} \mathrm{~d}^{-1}\right)$ received by each treatment over the whole experiment period. Daily PAR exposure was corrected for shade, light attenuation of the lake, transmittance of the incubation bottles and vertical motion of moved algae.

\begin{tabular}{|c|c|c|c|c|c|c|c|}
\cline { 2 - 8 } \multicolumn{1}{c|}{} & \multicolumn{2}{c|}{$0-0.5 \mathrm{~m}$} & \multicolumn{2}{c|}{$0-1 \mathrm{~m}$} & \multicolumn{2}{c|}{$0-1.8 \mathrm{~m}$} \\
\cline { 2 - 8 } \multicolumn{1}{c|}{} & surface & Fixed & Moved & Fixed & Moved & Fixed & Moved \\
\hline 7 Sept & 3.00 & 1.42 & 1.65 & 0.53 & 1.12 & 0.03 & 0.93 \\
$8 \mathrm{Sept}$ & 7.19 & 4.02 & 4.19 & 1.86 & 2.91 & 0.18 & 2.25 \\
$9 \mathrm{Sept}$ & 10.23 & 4.67 & 5.58 & 1.64 & 3.78 & 0.07 & 2.91 \\
$10 \mathrm{Sept}$ & 1.65 & 0.88 & 0.94 & 0.38 & 0.65 & 0.03 & 0.50 \\
11 Sept & 1.68 & 0.74 & 0.91 & 0.25 & 0.61 & 0.01 & 0.47 \\
13 Sept & 12.58 & 6.78 & 7.22 & 2.97 & 4.99 & 0.57 & 3.90 \\
14 Sept & 1.36 & 0.48 & 0.57 & 0.17 & 0.39 & 0.02 & 0.31 \\
15 Sept & 2.78 & 1.39 & 1.55 & 0.55 & 1.06 & 0.09 & 0.81 \\
16 Sept & 2.58 & 1.68 & 1.82 & 0.71 & 1.25 & 0.13 & 0.99 \\
\hline Average & 4.78 & 2.45 & 2.71 & 1.01 & 1.86 & 0.13 & 1.45 \\
\hline
\end{tabular}


Appendix-Table 3. Averaged relative contributions of the main phytoplankton groups to the total biovolume under constant and fluctuating light across the entire experimental period.

\begin{tabular}{|c|c|c|c|c|c|c|}
\cline { 2 - 7 } \multicolumn{1}{c|}{} & \multicolumn{3}{c|}{ Constant light } & \multicolumn{3}{c|}{ Fluctuating light } \\
\cline { 2 - 7 } & Cyanobacteria & Diatoms & Chlorophyceae & Cyanobacteria & Diatoms & Chlorophyceae \\
\hline $\begin{array}{c}\text { Minimal } \\
\text { contribution }\end{array}$ & 0.10 & 0.38 & 0 & 0.14 & 0.55 & 0 \\
\hline $\begin{array}{c}\text { Maximal } \\
\text { contribution }\end{array}$ & 0.46 & 0.90 & 0.21 & 0.43 & 0.85 & 0.04 \\
\hline $\begin{array}{c}\text { Mean } \pm \\
\text { Standard } \\
\text { deviation }\end{array}$ & $0.27 \pm 0.11$ & $0.69 \pm 0.14$ & $0.04 \pm 0.05$ & $0.25 \pm 0.09$ & $0.73 \pm 0.1$ & $0.02 \pm 0.01$ \\
\hline
\end{tabular}




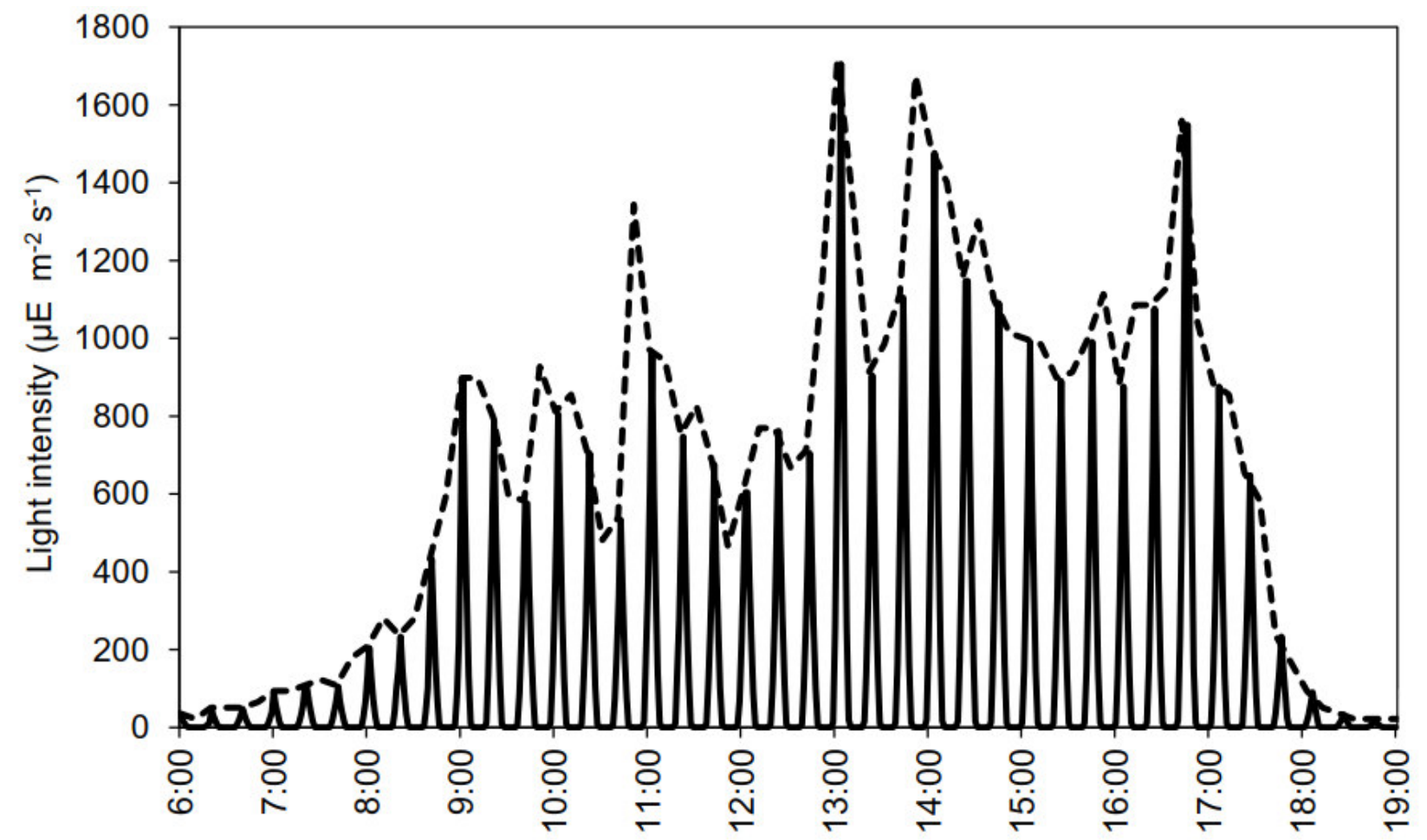

Appendix - Figure 1. Example of diurnal course of light intensity at the water surface (dotted line) and experienced by phytoplankton under complete water column mixing (0$1.8 \mathrm{~m}$ ) (full line) for the two extreme light supply treatments taken at the Lake station, $7^{\text {th }}$ September 2016 (attenuation coefficient $=4.97 \mathrm{~m}^{-1}$ ). Phytoplankton received $3 \mathrm{E} \mathrm{m}^{-2} \mathrm{~d}^{-1}$ (100\% PAR relative) at the surface versus $0.93 \mathrm{E} \mathrm{m}^{-2} \mathrm{~d}^{-1}$ (30.9\% PAR relative) for the case of full over-turn. 


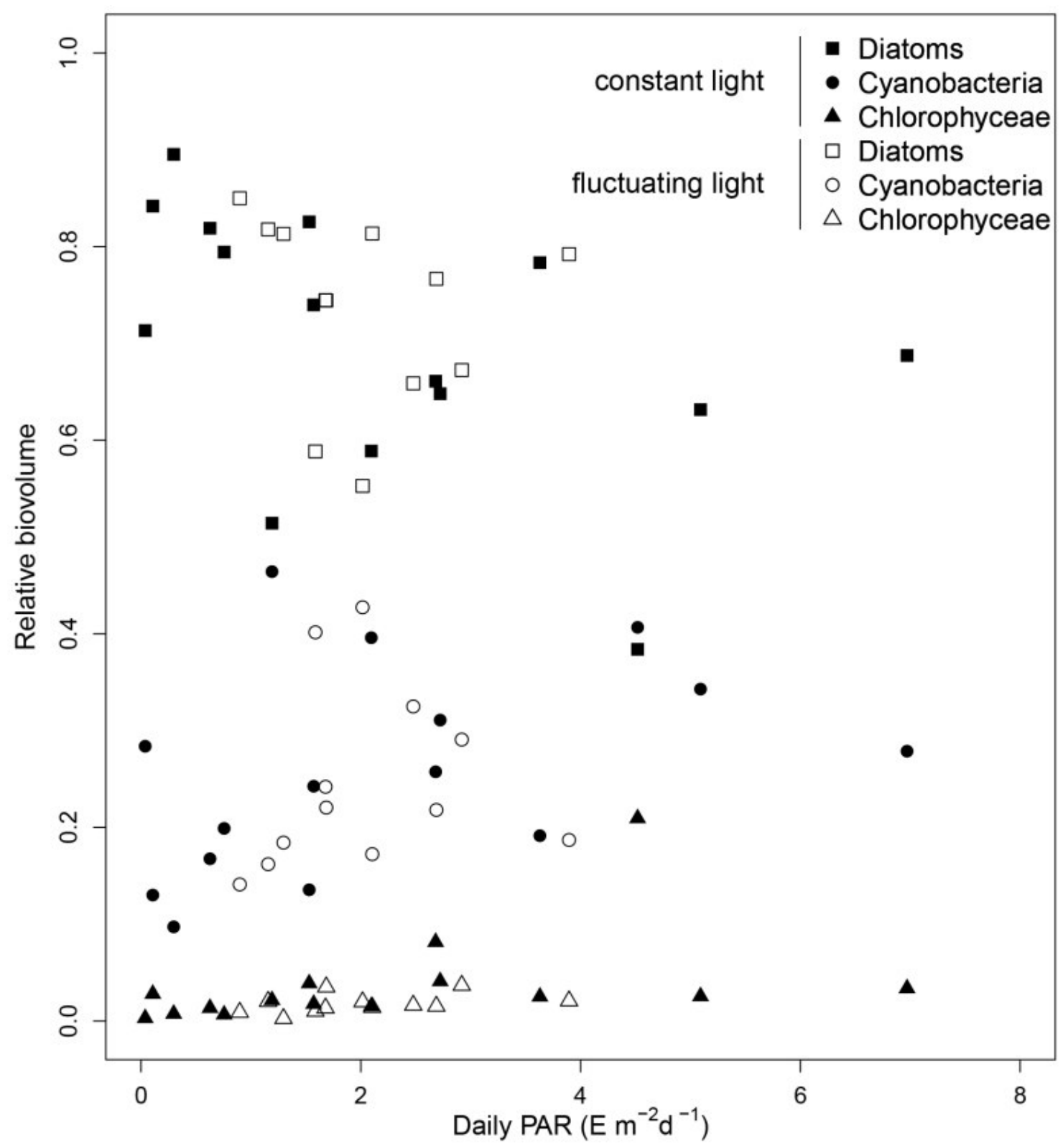

Appendix - Figure 2. Light-dependency of the relative biovolumes of diatoms, cyanobacteria and chlorophyceae to the total biovolume, under fluctuating (open symbols) and constant light (closed symbols). Averages over [day 0 - day 1] and [day 2 - end experiment] represented the relative contributions at day 2 and at the end of the experiment respectively. 


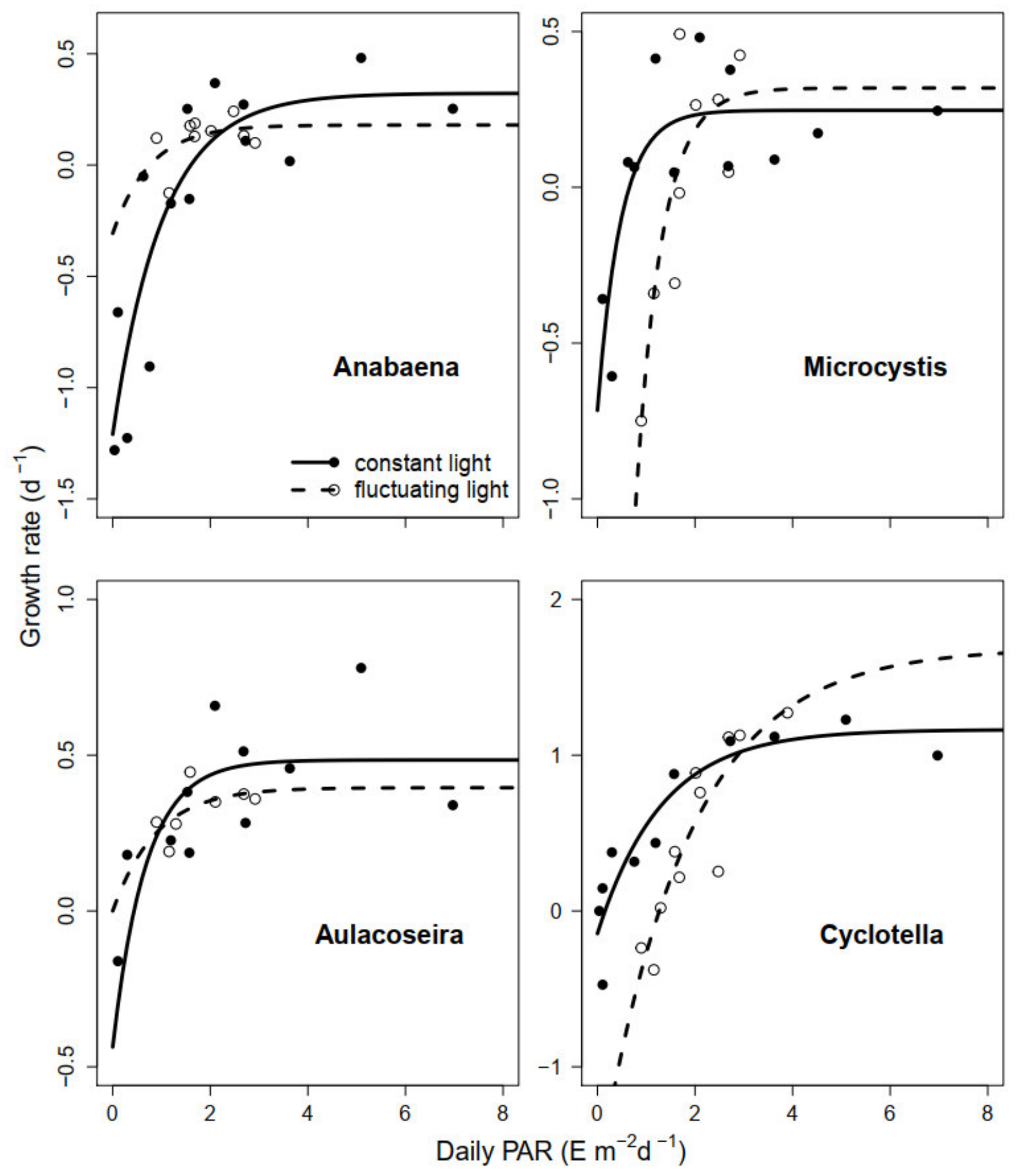

Appendix - Figure 3. Species-specific growth-light relationships of Anabaena flos-aquae, Microcystis spp., Aulacoseira granulata and Cyclotella pseudostelligera under fluctuating and constant light. 